\title{
Intravenous thrombolysis is more effective in ischemic cardioembolic strokes than in non-cardioembolic?
}

\author{
Sofia Rocha', Arnaldo Pires², Joana Gomes³, João Rocha', Filipa Sousa', \\ João Pinho', Margarida Rodrigues' ', Carla Ferreira', Álvaro Machado', \\ Ricardo Maré', João Ramalho Fontes ${ }^{1}$
}

\begin{abstract}
It was suggested that intravenous thrombolysis (IT) leads to larger extent recanalization in cardioembolic stroke. In this work we assess if this has beneficial clinical traduction. Method: We evaluated 177 patients undergoing IT, which were categorized into cardioembolic (CE) and non-cardioembolic (NCE). National Institutes of Health Stroke Scale (NIHSS) and modified Rankin scale were compared. Results: The mean age was $67.4 \pm 12.01$ and $53.8 \%$ were male. The mean NIHSS was: 14 (admission), 9 (24 h) and 6 (discharge), similar in subgroups. The difference between NIHSS at admission and 24 hours was $4.17 \pm 4.92$ (CE: $4.08 \pm 4.71 ; \mathrm{NCE}: 4.27 \pm 5.17, \mathrm{p}=0.900$ ) and at admission and discharge there was an average difference of $6.74 \pm 5.58$ (CE: $6.97 \pm 5.68$; NCE: $6.49 \pm 5.49, p=0.622$ ). The mRS at discharge and 3 months was not significantly different by subtype, although individuals whose event was NCE are more independent at 3 months. Conclusion: Ours findings argue against a specific paper of IT in CE. It can result from heterogeneity of NCE group. Key words: cardioembolism, stroke, thrombolysis.
\end{abstract}

A trombólise endovenosa é mais eficaz nos acidentes vasculares cerebrais isquêmicos cardioembólicos do que nos não cardioembólicos?

\section{RESUMO}

Alguns estudos sugerem que a trombólise endovenosa (TE) conduz a melhor recanalização nos acidentes vasculares cerebrais isquêmicos (AVCl) cardioembólicos. Neste trabalho questionamos se isto terá tradução em benefício clínico. Método: Avaliamos 177 doentes submetidos a TE, os quais foram categorizados como cardioembólicos (CE) e não cardioembólicos (NCE). Compararam-se a National Institutes of Health Stroke Scale (NIHSS) e escala de Rankin modificada. Resultados: A idade média foi 67,4 412,01 e $53,8 \%$ eram homens. NIHSS média foi: 14 (admissão), 9 (24 h), 6 (alta), semelhante nos

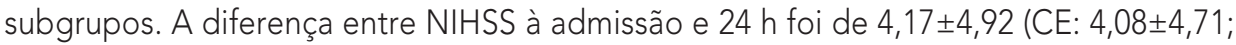
NCE: $4,27 \pm 5,17, p=0,900$ ) e entre a admissão e a alta de 6,74 $\pm 5,58$ (CE: 6,97 $\pm 5,68$; NCE: $6,49 \pm 5,49, p=0,622)$. A classificação na mRS não foi significativamente diferente nos subgrupos (alta e 3 meses), mas os doentes com eventos NCE estavam mais independentes aos 3 meses. Conclusão: Os nossos resultados não documentam um papel específico da TE nos CE, o que pode resultar da heterogeneidade do grupo NCE. Palavras-Chave: cardioembolismo, acidente vascular cerebral, trombólise.

\section{Correspondence}

Sofia Rocha Hospital de Braga, Sete Fontes, São Victor 4710-243 Braga - Portugal E-mail: sofiar@ufp.edu.pt

Received 10 February 2011 Received in final form 17 June 2011 Accepted 24 June 2011
Stroke incidence in rural and urban Northern Portugal is high compared to that reported in other Western Europe regions ${ }^{1}$ As ischemic stroke results from artery occlusion, repermeabilization is the main therapeutic target, and early recanalization seems to increase clinical recovery and to diminish long-term disability ${ }^{2-5}$.

${ }^{1} \mathrm{MD}$, Neurology Department, Braga Hospital, Braga, Portugal; ${ }^{2} \mathrm{MD}$, Internal Medicine Department, Braga Hospital, Braga, Portugal; ${ }^{3} \mathrm{MD}$, Epidemiology Department, Porto Medicine University, Porto, Portugal. 
Intravenous thrombolysis in acute ischemic stroke is effective in improving functional measures and neurologic outcome in a defined subgroup of stroke patients with moderate to severe neurologic deficit and without extense infarct on initial CT $\operatorname{scan}^{6}$. Although intravenous thrombolysis with alteplase (rt-PA) is the most effective treatment for acute ischemic stroke, the benefit can vary according to size, composition and origin of thrombus ${ }^{7}$. Old clots rich in platelets, well organized and formed in flow conditions are more resistant than fresh clots, rich in fibrin and blood cells, and formed under conditions of stasis ${ }^{8}$. Previous evidence suggests that rt-PA produces earlier, faster and larger recanalization in middle cerebral artery cardioembolic strokes as compared with other subtypes $^{7}$. In this study we aim to assess if this fact has any clinical translation, that is, if patients with cardioembolic stroke have an additional clinical benefit from rt-PA.

\section{METHOD}

We included all patients treated with rt-PA for ischemic stroke at our Hospital, between February 9, 2007 and May 18, 2010, in a total of 177 individuals. Twenty one patients were excluded from analysis because they did not complete the etiological investigation (14 were transferred to other hospitals and seven died before this).

Data related to gender, age, etiology according to TOAST criteria ${ }^{9}$, National Institutes of Health Stroke Scale (NIHSS) at admission, 24 hours and discharge and modified Rankin scale (mRS) at discharge and three months, were prospectively collected.

For the etiologic classification, we carried out electrocardiogram, transthoracic and/or transesophageal ecocardiogram, cervical Doppler and Holter (in selected cases). Final classification was done by a stroke neurologist.

For statistical analysis, the population was divided in two groups cardioembolic (CE) and non-cardioembolic (NCE), and characterized regarding age, gender and vascular risk factors. We compared NIHSS at admission, $24 \mathrm{~h}$ and discharge. NIHSS difference between admission and 24 hours, and admission NIHSS and discharge, were calculated. Rankin at discharge and at three months after thrombolysis was also compared between groups.

Statistical analysis was performed with SPSS 18.0, using the Chi-square test $\left(x^{2}\right)$, Mann-Whitney and ttest for difference of means in independent samples, as appropriate.

\section{RESULTS}

During the study period, intravenous thrombolysis was performed in 177 subjects of which 81 were classified as cardioembolic (51.9\%). Twenty-one individuals were excluded from analysis for not having completed the etiological investigation.
Table 1. Comparison of the mean NIHSS at admission, 24 hours and discharge.

\begin{tabular}{lcccc}
\hline & Total & CE & NCE & p \\
\hline $\begin{array}{lccc}\text { NIHSS } \\
\text { admission }\end{array}$ & $14(13.68)$ & $15(14.67)$ & $13(12.61)$ & 0.272 \\
$\begin{array}{l}\text { NIHSS } \\
24 \text { hours }\end{array}$ & $9(9.30)$ & $11(10.47)$ & $8(8.04)$ & 0.737 \\
$\begin{array}{l}\text { NIHSS } \\
\text { discharge }\end{array}$ & $6(6.44)$ & $7(7.23)$ & $6(5.61)$ & 0.149 \\
\hline
\end{tabular}

CE: cardioembolic; NCE: non-cardioembolic.

Patients mean age was 67.4 $\pm 12: 01$ (CE: $69.3 \pm 11.65$; NCE: $65.44 \pm 12.14 ; p=0.268)$. Eighty four individuals were males (53.8\%); 41 (50.6\%) in CE, 43 (57.3\%) in NCE; $\mathrm{p}=0.401$. Eighty six subjects were hypertensive (55.1\%); 46 (56.8\%) in CE, 40 (53.3\%) in NCE; $p=0.664$. Thirtyone patients (19.9\%) were diabetic, with a higher prevalence in the NCE group (22 subjects, 29.3\%), the difference reaching statistical meaning $(\mathrm{p}=0.004)$.

The mean symptom-needle time was $139.9 \pm 42.50$ minutes (CE: $143.4 \pm 35.39$; NCE: $136.3 \pm 48.94 ; \mathrm{p}=0.203$ ). The mean door-needle time was $52.6 \pm 16: 56$ minutes (CE: 7.97 \pm 54.0 ; NCE: $51.2 \pm 14.95 ; \mathrm{p}=0.611$ ).

The mean NIHSS at admission, 24 hours, and at discharge was not statistically different between CE and NCE (Table 1). NIHSS at admission and at 24 hours was subdivided, but still no significant differences were found (Table 2).

The mean difference between NIHSS at admission and at 24 hours was $4.92 \pm 4: 17$ (CE: 4.08 \pm 4.71 ; NCE: $4.27 \pm 5.17 ; \mathrm{p}=0.900)$. The mean difference between NIHSS at admission and discharge was 6.74 $\pm 5: 58$ (CE: 6.97 \pm 5.68 ; NCE: 6.49 $\pm 5.49 ; \mathrm{p}=0.622$ ) (Table 3).

Disability after stroke according to $\mathrm{mRS}$ at discharge was not significantly different by subtype $(\mathrm{p}=0.305)$. At 3 months there were also no significant differences between groups $(\mathrm{p}=0.135)$. When comparing independent $(m R S \leq 2)$ with dependent $(m R S>2)$ patients, there was no significant differences at discharge $(\mathrm{p}=0.509)$, but the NCE group has more independent individuals at 3 months ( $\mathrm{p}=0.037)$ (Table 4).

\section{DISCUSSION}

Early recanalization seems to lead to lower infarct size and a better clinical outcome ${ }^{2,3,5}$. Moreover, early recovery after recanalization after rt-PA is sustained at three months in most patients ${ }^{4}$. So, in fact, early recanalization is a powerful independent predictor of functional independence at three months ${ }^{3}$. This is mostly because of faster and more complete clot breakup with low resistance of the distal circulatory bed ${ }^{5}$. In the other hand, fewer patients achieve good long-term outcome without early recanalization ${ }^{4}$. 
Table 2. Mean age, gender, hypertension (HT), diabetes mellitus (DM), NIHSS at admission, 24 hours, and discharge, by cardioembolic and non-cardioembolic subtypes.

\begin{tabular}{|c|c|c|c|c|}
\hline & $\begin{array}{l}\text { All events } \\
(n=156)\end{array}$ & $\begin{array}{c}\text { Cardioembolics } \\
(\mathrm{n}=81 ; 51.9 \%)\end{array}$ & $\begin{array}{c}\text { Non-cardioembolics } \\
(n=75 ; 48.1 \%)\end{array}$ & $\mathrm{p}$ \\
\hline Mean age (age \pm standard deviation) & $67.4 \pm 12.01$ & $69.3 \pm 11.65$ & $65.44 \pm 12.14$ & 0.268 \\
\hline \multicolumn{5}{|l|}{ Gender } \\
\hline Men $[n(\%)]$ & $84(53.8)$ & $41(50.6)$ & $43(57.3)$ & 0.401 \\
\hline $\mathrm{HT}[\mathrm{n}(\%)]$ & $86(55.1)$ & $46(56.8)$ & $40(53.3)$ & 0.664 \\
\hline $\mathrm{DM}[\mathrm{n}(\%)]$ & $31(19.9)$ & $9(11.1)$ & $22(29.3)$ & 0.004 \\
\hline NIHSS at admission [n(\%)] & & & & 0.142 \\
\hline $0-5$ & $6(3.8)$ & $3(3.7)$ & $3(4.0)$ & \\
\hline $6-10$ & $45(28.8)$ & $17(21.0)$ & $28(37.3)$ & \\
\hline $11-15$ & $42(26.9)$ & $22(27.1)$ & $20(26.7)$ & \\
\hline $16-20$ & $43(27.6)$ & $28(27.1)$ & $15(20.0)$ & \\
\hline$>21$ & $19(12.2)$ & $11(13.6)$ & $8(16.7)$ & \\
\hline Unknwon & $1(0.6)$ & $0(0.0)$ & $1(1.3)$ & \\
\hline NIHSS at 24hours [n(\%)] & & & & 0.106 \\
\hline $0-5$ & $56(35.9)$ & $24(29.6)$ & $32(42.7)$ & \\
\hline $6-10$ & $30(19.2)$ & $13(16.0)$ & $17(22.7)$ & \\
\hline $11-15$ & $29(18.6)$ & $19(23.4)$ & $10(13.3)$ & \\
\hline $16-20$ & $25(16.0)$ & $17(21.0)$ & $8(10.7)$ & \\
\hline$>21$ & $11(7.1)$ & $5(6.2)$ & $6(8.0)$ & \\
\hline Unknwon & $5(3.2)$ & $3(3.7)$ & $2(2.7)$ & \\
\hline NIHSS at discharge [n(\%)] & & & & 0.424 \\
\hline $0-5$ & $81(51.9)$ & $38(46.9)$ & $43(57.3)$ & \\
\hline $6-10$ & $24(15.4)$ & $12(14.8)$ & $12(16.0)$ & \\
\hline $11-15$ & $20(12.8)$ & $11(13.6)$ & $9(12.0)$ & \\
\hline $16-20$ & $17(10.9)$ & $11(13.6)$ & $6(8.0)$ & \\
\hline$>21$ & $2(1.3)$ & $2(2.5)$ & $0(0.0)$ & \\
\hline Unknwon & $12(7.7)$ & $7(8.6)$ & $5(6.7)$ & \\
\hline Rankin at discharge [n(\%)] & & & & 0.305 \\
\hline 0 & $30(19.2)$ & $10(12.3)$ & $20(26.7)$ & \\
\hline 1 & $22(14.1)$ & $13(16.0)$ & $9(12.0)$ & \\
\hline 2 & 29 (18.6) & $17(21.0)$ & $12(16.0)$ & \\
\hline 3 & $27(17.3)$ & $12(14.8)$ & $15(20.0)$ & \\
\hline 4 & $35(22.4)$ & $21(26.0)$ & $14(18.7)$ & \\
\hline 5 & $3(1.9)$ & $2(2.5)$ & $1(1.3)$ & \\
\hline 6 & $10(6.4)$ & $6(7.4)$ & $4(5.3)$ & \\
\hline Rankin at three months [n(\%)] & & & & 0.135 \\
\hline 0 & $27(17.3)$ & 14 (17.3) & $13(17.3)$ & \\
\hline 1 & 24 (15.4) & 7 (8.6) & 17 (22.7) & \\
\hline 2 & $25(16.0)$ & $13(16.0)$ & $12(16.0)$ & \\
\hline 3 & 19 (12.2) & $13(16.0)$ & $6(8.0)$ & \\
\hline 4 & $15(9.6)$ & $10(12.3)$ & $5(6.7)$ & \\
\hline 5 & $1(0.6)$ & $0(0.0)$ & $1(1.3)$ & \\
\hline 6 & 17 (10.9) & 10 (12.3) & 7 (9.3) & \\
\hline Unknwon & 28 (17.9) & $14(17.3)$ & $14(18.7)$ & \\
\hline
\end{tabular}

NIHSS: National Institutes of Health Stroke Scale. 
Table 3. Comparison of the differences between NIHSS at admission - 24 hours and at admission - discharge.

\begin{tabular}{lcccc}
\hline & $\begin{array}{c}\text { All events } \\
(\mathrm{n}=156)\end{array}$ & $\begin{array}{c}\text { Cardioembolics } \\
(\mathrm{n}=81 ; 51.9 \%)\end{array}$ & $\begin{array}{c}\text { Non-Cardioembolics } \\
(\mathrm{n}=75 ; 48.1 \%)\end{array}$ & $\mathrm{p}$ \\
\hline Difference NIHSS admission - 24 hours & 4.17 & 4.08 & 4.27 & 0.900 \\
Difference NIHSS admission - discharge & 6.74 & 6.97 & 6.49 & 0.622 \\
\hline
\end{tabular}

NIHSS: National Institutes of Health Stroke Scale.

Table 4. Comparison of modified Rankin scale at discharge and at three months.

\begin{tabular}{|c|c|c|c|c|}
\hline & $\begin{array}{l}\text { All events } \\
(n=156)\end{array}$ & $\begin{array}{l}\text { Cardioembolics } \\
(\mathrm{n}=81 ; 51.9 \%)\end{array}$ & $\begin{array}{l}\text { Non-Cardioembolics } \\
\quad(n=75 ; 48.1 \%)\end{array}$ & $\mathrm{p}$ \\
\hline \multicolumn{5}{|c|}{ Rankin at discharge [n(\%)] } \\
\hline$\leq 2$ & $81(51.9)$ & $40(49.4)$ & $41(54.7)$ & 0.509 \\
\hline$>2$ & $75(48.1)$ & $41(50.6)$ & $34(45.3)$ & \\
\hline Unknown & $0(0.0)$ & $0(0.0)$ & $0(0.0)$ & \\
\hline \multicolumn{5}{|c|}{ Rankin three months [n(\%)] } \\
\hline$\leq 2$ & $76(48.7)$ & $34(42.0)$ & $42(56.0)$ & 0.037 \\
\hline$>2$ & $52(33.3)$ & $33(40.7)$ & $19(25.3)$ & \\
\hline Unknown & $28(17.9)$ & $14(17.3)$ & $14(18.7)$ & \\
\hline
\end{tabular}

Molina et al., compared the time, speed and degree of rt-PA induced recanalization in patients with proximal middle cerebral artery occlusion of different subtypes ${ }^{7}$. In this study, the authors, using transcranial doppler, monitored the recanalization during rt-PA infusion and at six hours, comparing large-vessel disease strokes, cardioembolic strokes and strokes of undetermined origin. One-hour recanalization was more frequent in patients with cardioembolic stroke compared with the other subtypes. Rate of complete recanalization at six hours was also higher in cardioembolic stroke. Thus, it was demonstrated that the pattern of rt-PA induced middle cerebral artery recanalization differs among stroke subtypes. The authors also concluded that sudden recanalization was associated with a higher degree of neurological improvement at 24 hours and at long-term compared with stepwise, slow, or absent recanalization ${ }^{7}$.

Differential patterns of the speediness, degree and temporal profile of clot dissolution may reflect structural differences of the clots ${ }^{8}$. In this context, stroke subtypes may represent a surrogate of clot composition and differences in the response to rt-PA in terms of recanalization. Cardioembolic stroke probably represents the stroke subtype with more uniform fibrin-rich clots, given the high binding affinity of rt-PA for fibrin. In contrast, in well organized and platelet-rich clots, penetration and distribution of rt-PA are limited. In the other hand, the presence of an extracranial internal carotid artery occlusion might hamper the delivery of an adequate dose of rt-PA into the ipsilateral occlude middle cerebral artery ${ }^{7}$.

Hsia et al., achieved the relationship between final stroke subtype (after diagnostic evaluation has been completed) and response to thrombolytic therapy. They concluded that the efficacy of intravenous thrombolysis within the threee hours time window is similar between different stroke subtypes ${ }^{10}$.

In our study, no significant differences were found between NIHSS at admission, 24 hours and three months, by subgroups. However, in our population, patients with non-cardioembolic events are more independent for daily life activities at three months. In our study, we didn't assess recanalization because transcranial doppler monitoring was not performed during thrombolysis, and stroke subtypes were not adjusted by stroke severity and location of arterial occlusion. Furthermore, in our study we compared cardioembolic with non-cardioembolic events, while in the study work up by Molina et al. ${ }^{7}$ it was compared cardioembolic events with events classified as "large vessels disease" and as "undetermined origin". Clots from cardioembolism are theoretically richer in fibrin and therefore more prone to thrombolytic fixation, while occlusion in large vessels disease are mostly caused by very organized platelets rich clots, which are more difficult to dissolve. However, in our study, the non-cardioembolic group includes events whose occlusion could have been caused by clots of intermediate features, because this group can include other stroke etiology beyond large vessel disease.

Based on our results, we concluded that early neurological recovery, at 24 hours and at discharge, measured by NIHSS and mRS was not significant different between stroke subtypes. Thus, we hypothesize that the pattern of rt-PA induced recanalization did not differ among cardioembolic and non cardioembolic strokes. 
Moreover, recovery at long term, measured by mRS at three months, seems to be better in non-cardioembolic strokes. Thus, the specific role of intravenous thrombolysis in different stroke subtypes still needs to be clarified in larger prospective trials.

\section{REFERENCES}

1. Correia M, Silva MR, Matos I. Prospective community-based study of stroke in northern Portugal. Incidence and cases fatality in rural and urban populations. Stroke 2004;35:2048-2053.

2. Christou I, Alexandrov AV, Burgin WS. Timing of recanalization after tissue plasminogen activator therapy by transcranial Doppler correlats with clinical recovery from ischemic stroke. Stroke 2000;31:1812-1816.

3. Molina CA, Montaner J, Abilleira S. Time course of tissue plaminogen activator-induced recanalization in acute cardioembolic stroke: a case control study. Stroke 2001;32:2821-2827.

4. Labiche LA, Al-Senani F, Wojner AW, Grotta JC, Malkoff M, Alexandrov AV. Is the benefit of early recanalization sustained at 3 months? A prospective cohort study. Stroke 2003;34:695-698.
5. Alexandrov AV, Burgin WS, Demchuk AM, El-Mitwalli A, Grotta JC. Speed of intrancranial clot lysys with intravenous tissue plaminogen activator therapy. Sonographic classification and short-term improvement. Circulation 2001;103:2897-2902.

6. Hacke W, Kaste M, Fieschi C. Intravenous thrombolysis with recombinant tissue plasminogen activator for acute hemispheric stroke: the European Cooperative Acute Stroke Study (ECASS). JAMA 1995;274:1017-1025.

7. Molina CA, Montaner J, Arenillas JF, Ribo M, Rubiera M, Alvarez-Sabín J. Differential pattern of tissue plasminogen activator-induced proximal middle cerebral artery recanalization among stroke subtypes. Stroke 2004;35:486-490.

8. Wu JH, Siddiqui K, Diamond SL. Transport phenomena and clot dissolving therapy: an experimental investigation of diffusion-controlled and permeation-enhanced fibrinolysis. Thromb Haemost 1994;72:105-112.

9. Albanese MA, Clarke WR, Adams HP Jr, Woolson RF. Ensuring realiability of outcome measures in multicenter clinical trials of treatments for acute ischemic stroke: the program developds for the trial of Org 10172 in Acute Stroke Treatment (TOAST). Stroke 1994;25:1746-1751.

10. Hsia AW, Sachdev HS, Tomlinson J, Hamilton SA, Tong DC. Efficacy of IV tissue plaminogen activator in acute stroke: does stroke subtype really matter? Neurology 2003:8:61:71-75. 